\title{
Adherence to yoga and exercise interventions in a 6-month clinical trial
}

\author{
KE Flegal1 ${ }^{1}$, S Kishiyama1 ${ }^{1}$ D Zajdel ${ }^{1}$, M Haas $^{3}$ and BS Oken*1,2
} Address: ${ }^{1}$ Department of Neurology, Oregon Health \& Science University, Portland, USA, ${ }^{2}$ Department of Behavioral Neuroscience, Oregon
Health \& Science University, Portland, USA and ${ }^{3}$ Center for Outcome Studies, Western States Chiropractic College, Portland, USA

Email: KE Flegal - kflegal@umich.edu; S Kishiyama - sskishiyama@comcast.net; D Zajdel - zajdeld@ohsu.edu; M Haas - mhaas@wschiro.edu; BS Oken* - oken@ohsu.edu

* Corresponding author

\section{Published: 9 November 2007}

BMC Complementary and Alternative Medicine 2007, 7:37 doi:10.1 186/1472-6882-7-37

This article is available from: http://www.biomedcentral.com/1472-6882/7/37

(C) 2007 Flegal et al; licensee BioMed Central Ltd.

This is an Open Access article distributed under the terms of the Creative Commons Attribution License (http://creativecommons.org/licenses/by/2.0), which permits unrestricted use, distribution, and reproduction in any medium, provided the original work is properly cited.
Received: 2I May 2007

Accepted: 9 November 2007

\begin{abstract}
Background: To determine factors that predict adherence to a mind-body intervention in a randomized trial.

Design: We analyzed adherence data from a 3-arm trial involving 135 generally healthy seniors 65-85 years of age randomized to a 6-month intervention consisting of: an lyengar yoga class with home practice, an exercise class with home practice, or a wait-list control group. Outcome measures included cognitive function, mood, fatigue, anxiety, health-related quality of life, and physical measures. Adherence to the intervention was obtained by class attendance and biweekly home practice logs.
\end{abstract}

Results: The drop-out rate was 13\%. Among the completers of the two active interventions, average yoga class attendance was $77 \%$ and home practice occurred $64 \%$ of all days. Average exercise class attendance was $69 \%$ and home exercise occurred $54 \%$ of all days. There were no clear effects of adherence on the significant study outcomes (quality of life and physical measures). Class attendance was significantly correlated with baseline measures of depression, fatigue, and physical components of health-related quality of life. Significant differences in baseline measures were also found between study completers and drop-outs in the active interventions. Adherence was not related to age, gender, or education level.

Conclusion: Healthy seniors have good attendance at classes with a physically active intervention. Home practice takes place over half of the time. Decreased adherence to a potentially beneficial intervention has the potential to decrease the effect of the intervention in a clinical trial because subjects who might sustain the greatest benefit will receive a lower dose of the intervention and subjects with higher adherence rates may be functioning closer to maximum ability before the intervention. Strategies to maximize adherence among subjects at greater risk for low adherence will be important for future trials, especially complementary treatments requiring greater effort than simple pill-taking.

\section{Background}

Adherence is an important consideration in clinical trial design, especially concerning mind-body interventions. A meta-analysis of adherence to a range of medical interven- 
tions, not just drug therapy, found that adherence increases the likelihood of a good outcome by $26 \%[1]$ The effect of high adherence on better health outcomes has even been documented in the placebo arm of a double blind randomized trials [2-4]. Subject characteristics that determine adherence to drug treatment regimens and behavioral interventions have been found to include psychological states such as depression, anxiety, and psychological distress; cognitive-motivational factors such as health beliefs, intentions, and self-efficacy; somatic and cognitive appraisals such as perceived physical fitness and adverse side effects of a treatment; and health-oriented behaviors [5]. In a mind-body intervention, where greater effort than simple pill-taking is required, factors that predict adherence and strategies to maximize adherence deserve special attention. One reason is that adherence is lower with behavioral interventions than with pill-taking [6] and adherence may contribute to the effectiveness of the intervention. The other is that the relationship between adherence and health outcomes may itself be mediated through mind-body mechanisms, with potential roles for expectancy, self-efficacy, and interest in health promoting activities. These interactions, if not adequately controlled for, may potentially confound results of mind-body trials, especially since the trials are not blinded to the participants out of necessity. For example, if there is a large adherence effect on the outcomes, it may be necessary to stratify allocation to better match adherence in the groups. The present study investigates correlates of adherence to yoga and exercise interventions in a population of healthy seniors, contributing evidence for baseline measures including mood, physical functioning, general health, and fatigue impacting adherence rates and probability of study completion.

\section{Methods}

The adherence data presented here were collected from a recently reported 3-arm clinical trial [7]. The study consisted of 135 generally healthy men and women 65-85 years of age randomized to a 6-month intervention consisting of: an Iyengar yoga class along with home practice, an exercise class along with home practice, or a wait-list control group given the option of enrolling in either of the active interventions after the wait-list period. As reported [7], the yoga intervention produced improvement in quality of life and physical measures but not on cognition or mood.

Subjects in the yoga intervention were taught beginning Iyengar hatha yoga poses in weekly 90 -minute classes. Daily home practice was strongly encouraged, and subjects were given a booklet illustrating the specific poses to help with their independent practice [8]. Subjects in the exercise intervention engaged in aerobic walking on an outdoor track in weekly 60-minute classes. Daily home exercise in the same range of perceived exertion was encouraged at least 5 times per week. Subjects in the waitlist group participated in no active intervention. All subjects received monthly phone calls to assess for changes in health.

Baseline assessments of study outcome measures were performed before subjects were randomized and occurred 1 to 30 days before classes started. On the baseline visit, medical history was reviewed, demographic data were recorded, and the oral reading on the Wide Range Achievement Test, 3rd edition (WRAT-3) [9], was administered to assess equality of educational achievement in the three intervention groups. All outcome assessments were done at baseline and 6 months. There was also a 3month visit primarily designed to encourage subjects' continued participation in the study

Outcome measures included cognitive function, mood as assessed by Center for Epidemiologic Studies Depression Scale (CESD-10) [10] and Profile of Mood States (POMS) [11], fatigue as assessed by Multidimensional Fatigue Inventory (MFI-20) [12], state and trait anxiety (STAI) [13], health-related quality of life (SF-36) [14], and physical measures (seated forward bend, one legged-standing). Adherence to the each of the active interventions was obtained by class attendance and biweekly home practice logs. In a similar manner to other published trials of physical activity with measures of adherence (e.g., Martin and Sinden [15]) the percent of days home practice occurred (frequency) and the average length of home practice sessions (duration) were calculated.

\section{Results}

Subject demographics and adherence data are summarized in Table 1. 135 subjects were randomized and 118 completed the study by participating in the 6-month assessment, yielding a total drop-out rate of $13 \%$. Attrition rates from the yoga, exercise, and wait-list groups were $14 \%, 19 \%$, and $5 \%$, respectively, not significantly different by chi-square. Within the two active interventions, adherence data were available from 36 of the 38 completers in the yoga condition and all 38 completers in the exercise condition. For the yoga group, average attendance at classes was $77 \%$ and home practice occurred on $64 \%$ of all days, while for the exercise group class attendance was $69 \%$ and home exercise occurred on $54 \%$ of all days (or $76 \%$ of the five days a week it was recommended). The adherence differences between the yoga and the exercise group did not reach statistical significance (for percent attendance, $\mathrm{t}=-1.94, \mathrm{p}=0.056$ and for percent days practiced out of all days possible, $\mathrm{t}=-1.822, \mathrm{p}=$ 0.073 ). Home practice sessions lasted an average of 38 minutes for the yoga group and 56 minutes for the exercise group $(t=3.8, p=.0003)$. The objective measure of 
Table I: Subject demographics and adherence.

\begin{tabular}{lccc}
\hline & Exercise $(\mathrm{n}=47)$ & Yoga $(\mathrm{n}=44)$ & Wait-List $(\mathrm{n}=44)$ \\
\hline Age & $73.7 \pm 5.1$ & $71.5 \pm 4.9$ & $71.2 \pm 4.4$ \\
Gender & $79 \%$ female & $70 \%$ female & $75 \%$ female \\
Years of Education & $14.8 \pm 2.8$ & $15.5 \pm 2.2$ & $15.3 \pm 2.8$ \\
WRAT-3 Reading & $49.0 \pm 4.0$ & $48.7 \pm 4.3$ & $49.0 \pm 3.4$ \\
Measures of Adherence: & & & - \\
$\quad$ Percent Classes Attended & $69 \% \pm 19 \%$ & $77 \% \pm 20 \%$ & - \\
$\quad$ Percent Days Home Practice & $54 \% \pm 26 \%$ & $64 \% \pm 22 \%$ & - \\
$\quad$ Average Daily Home Practice (min.) & $56.1 \pm 26.4$ & $38.2 \pm 10.4$ & $14 \%$ \\
$\quad$ Study completer vs. drop-out (\% drop-out) & $19 \%$ & $5 \%$ & \\
\hline
\end{tabular}

Means \pm SDs are reported

class attendance was correlated with the self-report measures of adherence: number of days and length per day (Wilcoxon, $p^{\prime}$ s $<0.0005$ ). Class attendance was selected for the primary analyses because it was the most objective measure.

Adherence as measured by class attendance was significantly correlated with several baseline measures including mood, physical aspects of quality of life, and measures of fatigue (see Table 2). Higher baseline scores on self-rated measures of depression and fatigue were associated with lower class attendance during the 6 months of the intervention, while there was a positive relationship between adherence and self-rated measures of physical functioning, general health, vitality, and vigor at baseline.

Additionally, baseline measures of physical function and fatigue were significantly different between subjects who completed the study and those who dropped out (see Table 3). At baseline, those subjects who went on to complete the study scored higher on self-rated measures of physical functioning and general health, and lower on self-rated measures of trait anxiety and general fatigue, than those subjects who eventually dropped out. Of interest, completers had a higher mean baseline rating of bodily pain on the SF-36 questionnaire than did drop-outs.

Operationalized as either class attendance or study completion, adherence was not related to age, gender, or education level. There was no obvious effect of adherence on the significant outcomes from the intervention (quality of life and physical measures), defining class attendance continuously or as a threshold (adherers greater than $60 \%$ class attendance).

A limited number of subjects $(n=29)$ also completed a five-factor personality inventory, the NEO PI-R [16]. No significant relationships between adherence and personality were found (Pearson's correlation, all $\mathrm{p}$ values greater than 0.25), although the small sample size constrained the power to determine an effect.

\section{Discussion}

Consistent with other reports of behavioral treatments [17], adherence to yoga and exercise interventions in this clinical trial was significantly correlated with baseline variables including depression, fatigue, and physical aspects of quality of life. Demographic variables were not reliable predictors of adherence. It has been previously noted that factors that can be changed, such as mood and social support, more strongly influence adherence than factors that cannot, such as age and gender [18]. While adherence in the present study was relatively low compared to what might be expected in a drug trial, adherence has been observed to be generally lower in behavioral interventions and also with more objective adherence measures compared to self-report [18]. For this reason, we relied on objective class attendance as our primary adherence measure although the two self-reported measures were highly correlated with the objective measure.

The underlying mechanisms associated with greater adherence are not well understood. Because lower adherence, even in the placebo arm of a double blind trial, is associated with worse outcomes including greater mortality [2-4], it has been postulated that those with greater adherence may engage in many other health promoting behaviors. Thus, adherence may be a marker for a personality or related trait related to motivation or goal-directed behaviors. Self-efficacy, which may relate to motivation, is the perceived confidence in one's ability to accomplish a specific task [19]. While self-efficacy was not assessed in this study, it has been shown to be an important correlate of adherence [20]. Within the conceptual framework of self-efficacy, adherence is promoted by the belief that an intervention will be effective (the outcome expectancy) as well as the belief that the individual is capable of following the requirements of the intervention (the efficacy expectancy). When these expectations of success contribute to high self-efficacy, high adherence can result, and moreover, there is reciprocity; subjects who are highly adherent to an intervention may be strengthening their outcome and efficacy expectancies [21]. Expectancy of 
Table 2: Correlations of adherence (Percent Classes Attended) and baseline variables among study completers.

\begin{tabular}{|c|c|c|c|}
\hline & Exercise $(n=38)$ & Yoga $(n=36)$ & Both active interventions \\
\hline Age & -0.08 & 0.07 & -0.07 \\
\hline Gender & -0.20 & 0.12 & -0.05 \\
\hline Years of Education & -0.10 & -0.29 & -0.12 \\
\hline WRAT-3 Reading & 0.18 & -0.09 & 0.01 \\
\hline CES-D: 10 & -0.24 & -0.36 & -0.27 \\
\hline \multicolumn{4}{|l|}{ STAI } \\
\hline State Anxiety & -0.08 & -0.33 & -0.20 \\
\hline Trait Anxiety & -0.01 & -0.41 & -0.23 \\
\hline \multicolumn{4}{|l|}{ SF-36 } \\
\hline Physical Functioning & 0.21 & 0.52 & 0.38 \\
\hline Role-Physical & 0.31 & 0.23 & 0.27 \\
\hline Bodily Pain & 0.22 & 0.20 & 0.21 \\
\hline General Health & 0.15 & 0.31 & 0.23 \\
\hline Vitality & 0.23 & 0.38 & 0.32 \\
\hline Social Functioning & 0.17 & -0.04 & 0.09 \\
\hline Role-Emotional & 0.19 & 0.16 & 0.18 \\
\hline Mental Health & 0.17 & 0.13 & 0.13 \\
\hline Physical Composite & 0.25 & 0.41 & 0.33 \\
\hline Mental Composite & 0.15 & 0.09 & 0.13 \\
\hline \multicolumn{4}{|l|}{ POMS } \\
\hline Tension-Anxiety & 0.12 & -0.42 & -0.16 \\
\hline Depression-Dejection & -0.06 & -0.15 & -0.08 \\
\hline Anger-Hostility & 0.06 & -0.10 & -0.01 \\
\hline Vigor & 0.05 & 0.36 & 0.25 \\
\hline Fatigue & -0.11 & -0.52 & -0.34 \\
\hline Confusion & 0.01 & -0.23 & -0.12 \\
\hline Total Mood Disturbance & -0.01 & -0.36 & -0.20 \\
\hline \multicolumn{4}{|l|}{ MFI-20 } \\
\hline General Fatigue & -0.33 & -0.56 & -0.44 \\
\hline Physical Fatigue & -0.01 & -0.34 & -0.17 \\
\hline Reduced Activity & -0.06 & -0.38 & -0.21 \\
\hline Reduced Motivation & 0.06 & -0.37 & -0.17 \\
\hline Mental Fatigue & -0.09 & -0.32 & -0.19 \\
\hline
\end{tabular}

Correlation coefficients in bold are significant at $p<0.05$

outcome, besides contributing to adherence, is also a major component of the placebo effect $[22,23]$. Thus, investigations of factors that predict adherence (or, for that matter, all clinical investigations) are likely to benefit from a good measure of expectancy, which was absent in the present study. The relationship between adherence and health outcomes may be due to mechanisms underlying mind-body interactions, which makes this an area of special interest for researchers conducting mind-body interventions.

Many complementary treatments take a patient-centered approach and utilize outcome and efficacy expectancies, but also require greater effort than simple pill-taking, and this unique set of qualities recommends controlling for factors that impact adherence in mind-body interventions. A discussion of adherence to Mindfulness-Based Stress Reduction programs [24] has identified elements of the intervention itself such as active participation, personal follow-up, accommodation of individual preferences, and emphasis on process instead of outcome, which are believed to effectively discourage attrition and relapse. These are common elements to other mind-body therapies, including both physically active interventions in the present study, which may contribute to differences with conventional clinical trials in adherence and in outcomes.

Improving adherence in a mind-body intervention has the potential to enhance the treatment effect, by increasing 
Table 3: Active intervention completers and drop-outs compared on baseline variables.

\begin{tabular}{|c|c|c|c|}
\hline & Completers $(n=76)$ & Drop-outs $(n=15)$ & $p$-value \\
\hline Age & $72.4 \pm 5.1$ & $73.8 \pm 5.1$ & 0.33 \\
\hline Gender & $74 \%$ female & $80 \%$ female & 0.61 \\
\hline Years of Education & $15.0 \pm 2.4$ & $15.6 \pm 3.3$ & 0.48 \\
\hline WRAT-3 Reading & $48.9 \pm 3.9$ & $48.1 \pm 6.6$ & 0.63 \\
\hline CES-D:I0 & $4.9 \pm 3.8$ & $6.6 \pm 4.4$ & 0.14 \\
\hline \multicolumn{4}{|l|}{ STAI } \\
\hline State Anxiety & $28.5 \pm 8.6$ & $33.0 \pm 9.2$ & 0.07 \\
\hline Trait Anxiety & $29.5 \pm 7.7$ & $34.4 \pm 8.4$ & 0.03 \\
\hline \multicolumn{4}{|l|}{ SF-36 } \\
\hline Physical Functioning & $83.5 \pm 13.0$ & $72.5 \pm 14.1$ & 0.005 \\
\hline Role-Physical & $78.6 \pm 31.0$ & $67.9 \pm 34.6$ & 0.24 \\
\hline Bodily Pain & $74.8 \pm 19.3$ & $61.1 \pm 19.3$ & 0.02 \\
\hline General Health & $81.0 \pm 15.4$ & $65.1 \pm 13.7$ & 0.001 \\
\hline Vitality & $69.2 \pm 16.0$ & $65.7 \pm 12.4$ & 0.44 \\
\hline Social Functioning & $91.9 \pm 14.7$ & $88.4 \pm 18.0$ & 0.43 \\
\hline Role-Emotional & $82.0 \pm 29.0$ & $83.3 \pm 25.3$ & 0.87 \\
\hline Mental Health & $84.1 \pm 12.4$ & $81.4 \pm 12.4$ & 0.45 \\
\hline Physical Composite & $49.4 \pm 7.0$ & $42.7 \pm 6.9$ & 0.001 \\
\hline Mental Composite & $54.7 \pm 6.9$ & $55.5 \pm 6.3$ & 0.69 \\
\hline \multicolumn{4}{|l|}{ POMS } \\
\hline Tension-Anxiety & $0.8 \pm 4.3$ & $2.4 \pm 4.5$ & 0.19 \\
\hline Depression-Dejection & $4.3 \pm 5.4$ & $4.8 \pm 4.4$ & 0.77 \\
\hline Anger-Hostility & $3.7 \pm 5.0$ & $5.3 \pm 5.9$ & 0.31 \\
\hline Vigor & $20.4 \pm 4.8$ & $19.1 \pm 5.1$ & 0.37 \\
\hline Fatigue & $4.3 \pm 3.8$ & $5.6 \pm 4.9$ & 0.24 \\
\hline Confusion & $0.4 \pm 3.2$ & $0.6 \pm 2.4$ & 0.88 \\
\hline Total Mood Disturbance & $-6.9 \pm 19.8$ & $-0.4 \pm 21.4$ & 0.27 \\
\hline \multicolumn{4}{|l|}{ MFI-20 } \\
\hline General Fatigue & $8.5 \pm 3.5$ & $10.5 \pm 2.7$ & 0.04 \\
\hline Physical Fatigue & $7.8 \pm 3.0$ & $9.2 \pm 3.1$ & 0.11 \\
\hline Reduced Activity & $8.1 \pm 3.5$ & $9.5 \pm 3.1$ & 0.14 \\
\hline Reduced Motivation & $6.9 \pm 2.7$ & $8.1 \pm 3.9$ & 0.12 \\
\hline Mental Fatigue & $7.7 \pm 3.5$ & $8.8 \pm 2.7$ & 0.24 \\
\hline
\end{tabular}

Means \pm SDs are reported

the dose of the intervention received by all subjects, especially those who (because of lower baseline functioning) might sustain the greatest benefit and are at greater risk for low adherence. These same subjects who may be most in need of intervention may fail to even meet inclusion criteria for some clinical trials where high adherence during a screen-in period is required. In these cases, results of the intervention can be difficult to generalize and potential magnitude of the treatment effect may be obscured by the relatively high baseline health status of subjects who do pass the adherence run-in phase [3]. In the present study, subjects with a profile of self-reported baseline scores that was low on physical functioning and general health and high on fatigue were more likely to drop out, and less likely to maintain adherence if they did complete the study. This pattern of results accords with other published reports of factors that predict adherence to treatment, implying that at least some commonly identified determinants are equally relevant for mind-body interventions.

Reviews of efforts to improve adherence to therapeutic regimens have thus far been inconclusive, and suggest that no single approach is consistently effective for all subjects in all interventions $[25,26]$. Strategies to promote adherence include making instructions to subjects simpler and less demanding, addressing cognitive-motivational factors such as self-efficacy and health beliefs, offering social support and reinforcement, and providing reminders, with results suggesting that highest success rates are achieved by a combination of such approaches. Specific 
strategies may be particularly important for groups of subjects that may have more difficulty with adherence to behavioral interventions because of a variety of issues such as getting to a class, physical limitations, parental or caregiver responsibilities, or, as already discussed, depression. Concerns such as these may be especially relevant for elderly populations [27], like those tested in the present study, who stand to gain greatly from improvements in health. Continued attention to maximizing adherence is important for enhancing treatment benefits, as well as controlling the costs of clinical trials and increasing statistical power to determine the effectiveness of interventions [28].

This analysis examined study completion or attrition as well as adherence to the terms of a physically active intervention, and it may be that unique factors differentiate correlates of these related measures. As previously mentioned, lower adherence, even in the placebo arm of a double blind trial, is associated with worse outcomes [2$4]$, although the underlying mechanisms linking adherence to health outcomes are still unknown. Future trials may elucidate this relationship, which could be related to mind-body interactions.

\section{Conclusion}

Healthy seniors have reasonably good attendance at classes with a physically active intervention. There were no clear effects of adherence on the significant study outcomes (quality of life and physical measures). Adherence to the intervention was significantly correlated with baseline measures of depression, fatigue, and physical components of health-related quality of life. Adherence was not related to age, gender, or education level. Decreased adherence to a potentially beneficial intervention for fatigue or depression has the potential to decrease the effect of the intervention in a clinical trial because subjects who might sustain the greatest benefit will receive a lower dose of the intervention and subjects with higher adherence rates may be functioning better before the intervention. Strategies to maximize adherence among subjects at greater risk for low adherence will be important for future trials, especially complementary treatments requiring greater effort than simple pill-taking.

\section{Competing interests}

The author(s) declare that they have no competing interests.

\section{Authors' contributions}

KEF performed data analysis and drafted the manuscript. SS supervised subject recruitment and interventions, and obtained subject data. DZ supervised data management and obtained subject data. MH helped with overall design and execution of study. BSO conceived of the study, par- ticipated in its design and coordination. All authors read and approved the final manuscript.

\section{Acknowledgements}

This study was supported by NIH grant P50 AT00066, UI 9 AT002656, and MOI RR000334. Portions of this paper were presented at the 2006 North American Research Conference on Complementary and Integrative Medicine. Julie Lawrence and Kathleen Dehen provided the yoga intervention class and Joanne Leyva the exercise intervention class. The authors have reported no conflicts of interest.

\section{References}

I. DiMatteo MR, Giordani PJ, Lepper HS, Croghan TW: Patient adherence and medical treatment outcomes: a meta-analysis. Medical Care 2002, 40:794-8II.

2. Epstein LH: The direct effects of compliance on health outcome. Health Psychology 1984, 3:385-393.

3. Horwitz RI, Horwitz SM: Adherence to treatment and health outcomes. Archives of Internal Medicine 1993, 153:1863-8.

4. Simpson SH, et al.: A meta-analysis of the association between adherence to drug therapy and mortality. British Medical Journal 2006, 333:15-20.

5. Dunbar-Jacob JM, Schlenk EA, Burke LE, Matthews JT: Predictors of patient adherence: Patient characteristics. In The Handbook of Health Behavior Change Edited by: Shumaker SA, Schron EB, Ockene JK, McBee WL. New York: Springer Publishing Co.; 1998:49I-5II.

6. DiMatteo MR: Social Support and Patient Adherence to Medical Treatment: A Meta-Analysis. Health Psychology 2004, 23:207-218

7. Oken BS, et al.: Randomized controlled 6-month trial of yoga in healthy seniors. Alternative Therapies in Health and Medicine 2006, I 2:40-47.

8. Kishiyama $S$, et al.: Yoga as an experimental intervention for cognition in multiple sclerosis. International Journal of Yoga Therapy 2002, I 2:57-62.

9. Wilkinson GS: Wilmington, Delaware: Wide Range, Inc.; 1993.

10. Andresen EM, Malmgren JA, Carter WB, Patrick DL': Screening for depression in well older adults: evaluation of a short form of the CES-D (Center for Epidemiologic Studies Depression Scale). American Journal of Preventive Medicine 1994, 10:77-84.

II. McNair DM, Lorr M, Droppleman LF: Manual for the Profile of Mood States. San Diego, CA: EdITS/Educational and Industrial Testing Service; 1992.

12. Smets EM, Garssen B, Bonke B, De Haes JC: The Multidimensional Fatigue Inventory (MFI) psychometric qualities of an instrument to assess fatigue. Journal of Psychosomatic Research 1995, 39:3I5-25.

13. Spielberger C, Gorsuch R, Lushene R: The state trait anxiety inventory (STAI) test manual. Palo Alto, CA: Consulting Psychologists Press; 1983.

14. Ware JF: SF-36 Health Survey: Manual interpretation Guide. Boston: The Health Institute; 1993.

15. Martin KA, Sinden AR: Who will stay and who will go? A review of older adults' adherence to randomized controlled trials of exercise. Journal of Aging and Physical Activity 200I, 9:9I-II4.

16. Costa PT Jr, McCrae RR: Professional Manual: Revised NEO Personality Inventory (NEO PI-R) and NEO Five-Factor Inventory (NEO-FFI). Lutz, FL: Psychological Assessment Resources, Inc; 1992.

17. Davis MJ, Addis ME: Predictors of attrition from behavioral medicine treatments. Annals of Behavioral Medicine 1999, 21:339-49.

18. DiMatteo MR: Variations in patients' adherence to medical recommendations: a quantitative review of $\mathbf{5 0}$ years of research. Medical Care 2004, 42:200-209.

19. Bandura A: Self-Efficacy: The Exercise of Control. New York: W. H. Freeman and Company; 1997.

20. Buchmann WF: Adherence: a matter of self-efficacy and power. Journal of Advanced Nursing 1997, 26:132-137.

21. Czajkowski SM, Chesney MA, Smith AW: Adherence and the Placebo Effect. In The Handbook of Health Behavior Change Edited by: Shumaker SA, Schron EB, Ockene JK, McBee WL. New York: Springer Publishing Co.; 1998:409-423. 
22. Crow $R$, et al: The role of expectancies in the placebo effect and their use in the delivery of health care: a systematic review. Health Technology Assessment 1999, 3: I-48.

23. Oken BS, ed: Complementary Therapies in Neurology: an evidence-based approach. New York: Parthenon Publishing; 2004:199-230.

24. Salmon PG, Santorelli SF, Kabat-Zinn J: Intervention elements promoting adherence to mindfulness-based stress reduction programs in the clinical behavioral medicine setting. In The Handbook of Health Behavior Change Edited by: Shumaker SA, Schron EB, Ockene JK, McBee WL. New York: Springer Publishing Co.; 1998:239-266.

25. Roter $D$, et al:: Effectiveness of interventions to improve patient compliance: a meta-analysis. Medical Care 1998, 36: II38-1161.

26. McDonald HP, Garg AX, Haynes RB: Interventions to Enhance Patient Adherence to Medication Prescriptions: Scientific Review. JAMA 2002, 288:2868-2879.

27. Culos-Reed SN, Rejeski WJ, McAuley E, Ockene JK, Roter DL: Predictors of Adherence to Behavior Change Interventions in the Elderly. Controlled Clinical Trials 2000, 21:200S-205S.

28. Robiner WN: Enhancing adherence in clinical research. Contemporary Clinical Trials 2005, 26:59-77.

\section{Pre-publication history}

The pre-publication history for this paper can be accessed here:

http://www.biomedcentral.com/1472-6882/7/37/prepub

Publish with Biomed Central and every scientist can read your work free of charge

"BioMed Central will be the most significant development for disseminating the results of biomedical research in our lifetime. "

Sir Paul Nurse, Cancer Research UK

Your research papers will be:

- available free of charge to the entire biomedical community

- peer reviewed and published immediately upon acceptance

- cited in PubMed and archived on PubMed Central

- yours - you keep the copyright 